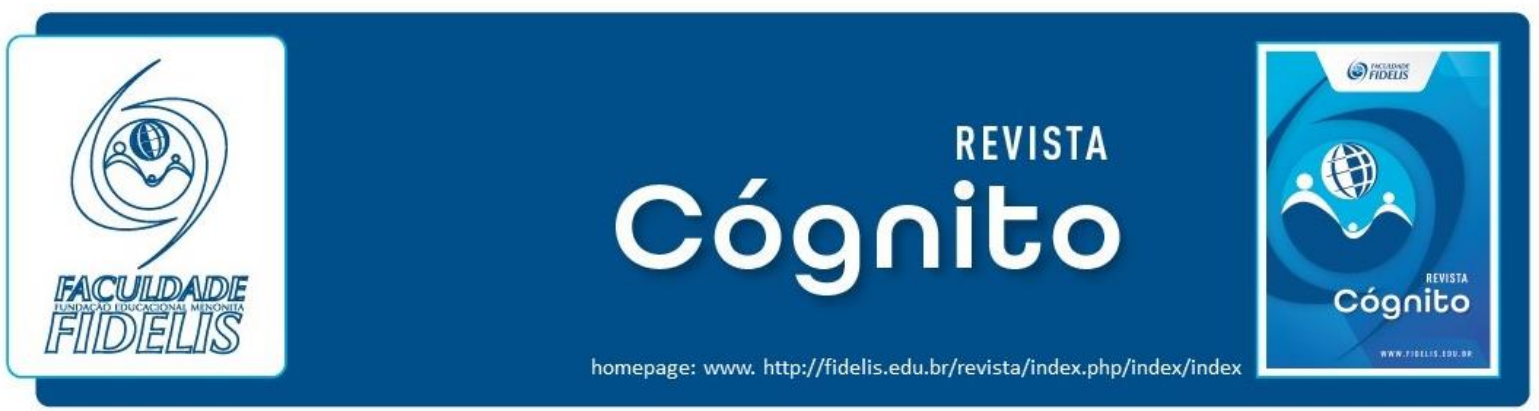

\title{
ERAM OS AMIGOS DE JÓ DE FATO SEUS AMIGOS?
}

WERE THE FRIENDS OF JOB INDEAD HIS FRIENDS?

\section{Hartmut August ${ }^{1}$}

\section{Análise do relacionamento entre Jó e seus amigos a partir da amizade entre Davi e Jônatas.}

\section{RESUMO}

Este ensaio analisa em que medida os amigos de Jó (Elifaz, Bildade, Zofar e Eliú) de fato podem ser considerados seus amigos solidários. Como parâmetros para esta análise são utilizadas as características encontradas na amizade entre Davi e Jônatas. Foram identificadas as seguintes atitudes cultivadas entre Davi e Jônatas: eles expressam mutuamente sua amizade; Jônatas intercede em favor de Davi; Jônatas protege, consola e sofre junto com Davi; e, finalmente, ambos permanecem leais ao outro, apesar das circunstâncias desfavoráveis. Aplicando estas características ao relacionamento entre Jó e seus amigos, observa-se que, no início, os companheiros de Jó expressam sua amizade a ele. Porém, esses seus amigos não intercedem em seu favor diante de Deus, não o protegem diante de Deus, não consolam Jó em seu sofrimento, não sofrem junto com ele e não lhe são leais. Desta forma, as atitudes de Elifaz, Bildade, Zofar e Eliú não podem ser caracterizadas como de uma amizade solidária em relação à Jó. A melhor designação para esses é de que se tratam de meros conhecidos de Jó. Eles sabem quem Jó é, vem ao seu encontro para prestar-lhe o luto protocolar, mas as demais atitudes não são características de uma amizade solidária.

PALAVRAS-CHAVE: Amizade. Luto. Jó.

\section{INTRODUÇÃO}

O livro de Jó "exprime o conceito antiquíssimo, profundo e injuntivo da relação ancestral entre Deus e o homem" (NEGRI, 2007, p. 46). Os personagens Elifaz, Bildade, Zofar

${ }^{1}$ Doutor em Teologia pela PUCPR. Docente da Faculdade Fidelis - hartmut.august@fidelis.edu.br 
e Eliú são apresentados como amigos de Jó. O presente artigo procura avaliar em que medida estes quatro amigos de fato se solidarizam, a ponto de Jó poder contar com eles em seus momentos de angústia e dor.

A Palavra de Deus relata diversos exemplos de pessoas que desenvolveram amizades exemplares. De acordo com o Dicionário do Aurélio Online (2010), amigo é a "pessoa a quem se está ligado por uma afeição recíproca". Um dos relacionamentos que melhor ilustra as características de uma amizade solidária é a relação entre Davi e Jônatas, uma das amizades mais belas dos textos bíblicos.

Portanto, este artigo se propõe a identificar quais as características que tornaram o relacionamento entre Davi e Jônatas numa amizade solidária e se estas mesmas características estão presentes no relacionamento entre Jó e seus amigos.

\section{O AMIGO SOLIDÁRIO EXPRESSA SUA AMIZADE}

Na ocasião em que Davi e Jônatas iniciam uma amizade duradoura, Jônatas era filho do rei Saul, ao passo que Davi estava a serviço do rei. Em 1Samuel 18.1-4 lemos que:

\footnotetext{
Depois dessa conversa de Davi com Saul, surgiu tão grande amizade entre Jônatas e Davi que Jônatas tornou-se o seu melhor amigo. Daquele dia em diante, Saul manteve Davi consigo e não o deixou voltar à casa de seu pai. E Jônatas fez um acordo de amizade com Davi, pois se tornara o seu melhor amigo. Jônatas tirou o manto que estava vestindo e o deu a Davi, com sua túnica, e até sua espada, seu arco e seu cinturão. $^{2}$
}

Jônatas sente-se tão ligado ao seu novo amigo que expressa sua afeição e seu compromisso dando a Davi seu manto, sua túnica, sua espada, seu arco e seu cinturão. Jônatas quer deixar evidente que a amizade com Davi é significativa para ele. Davi sabe que a amizade de Jônatas é sincera, pois Jônatas lhe dá provas concretas disto. Mesmo sem prever por quais situações irão passar no futuro, para ambos está claro que a amizade tem um preço a pagar. Os verdadeiros amigos expressam seu compromisso mútuo.

Analisando o relacionamento entre Jó e seus amigos Elifaz, Bildade, Zofar e Eliú, observa-se que os quatro amigos não ficam indiferentes ao sofrimento de Jó. Ao saberem da

\footnotetext{
${ }^{2}$ Todas as referências bíblicas deste artigo foram extraídas da Bíblia Sagrada, Nova Versão Internacional. São Paulo: Editora Vida, 2000.
} 
tragédia que se abate sobre ele, eles saem de suas terras distantes e combinam ir demonstrar solidariedade a Jó e lhe oferecer consolo (Jó 2.11). Assim que Elifaz, Bildade e Zofar veem Jó,

começaram a chorar em alta voz. Cada um deles rasgou seu manto e colocou terra sobre a cabeça. Depois os três se assentaram no chão com ele, durante sete dias e sete noites. Ninguém lhe disse uma palavra, pois viam como era grande o seu sofrimento (Jó 12.12b-13).

Os amigos de Jó deram do seu tempo, viajaram até onde ele estava e expressaram sua tristeza. Desta forma, o encontro de Jó com seus amigos é marcado por uma expressão sincera de amizade.

Portanto, vemos que tanto o relacionamento entre Davi e Jônatas como o relacionamento entre Jó e seus amigos são caracterizados por demonstrações concretas de afeição e interesse.

\section{O AMIGO SOLIDÁRIO INTERCEDE EM FAVOR DO AMIGO}

Quando o rei Saul pretende matar Davi, Jônatas intercede junto ao rei em favor deste seu amigo. O rei percebe que Davi está obtendo a admiração do povo e dos conselheiros em função de seus êxitos militares. Movido por inveja, "Saul falou a seu filho Jônatas e a todos os seus conselheiros sobre a sua intenção de matar Davi” (1Samuel 19.1). Jônatas imediatamente age para proteger seu amigo e o alerta do risco de vida que está correndo. Jonatas não apenas alerta Davi, mas também intercede por seu amigo diante do rei. Jonatas lembra ao seu pai dos "grandes benefícios" que ele trouxe ao rei, como ele arriscou sua vida quando matou o filisteu (1Samuel 19.2-5). Por mais que a iniciativa de Jônatas pudesse expô-lo diante do rei irado, Jônatas não hesita em interceder a favor do seu amigo, argumentando que Davi fora leal ao rei. A estratégia de Jônatas, embora arriscada na medida em que ele se expõe a ser também objeto da ira do rei, é bem-sucedida, pois "Saul atendeu a Jônatas e jurou, pelo nome do SENHOR, que Davi não será morto" (1Samuel 19.6). Em seguida, "Jônatas chamou Davi e lhe contou a conversa toda. Levou-o até Saul, e Davi voltou a servir a Saul como anteriormente. E houve guerra outra vez e Davi foi lutar contra os filisteus" (1Samuel 19.7,8). Assim, Jônatas intercede junto ao rei Saul em favor de Davi, mesmo colocando sua própria vida em risco.

Por outro lado, os amigos de Jó não se dispõem a interceder por ele diante de Deus. Eles compreendem que Jó está em conflito com Deus (Jó 5.1). Porém, na opinião de NEGRI (2007, p. 61), a atuação deles mais se assemelha a de advogados de Deus, na medida em que procuram 
razões para condenar seu amigo. Jó se ressente pelo fato de que seus amigos não intercedem por ele diante de Deus e argumenta que, "se fosse comigo, eu apelaria para Deus; apresentaria a ele a minha causa" (Jó 5.8). Bildade tira o corpo fora, pois afirma para Jó que "se você procurar a Deus e implorar junto ao Todo-poderoso, se você for íntegro e puro, ele se levantará agora mesmo em seu favor e o restabelecerá no lugar que por justiça cabe a você” (Jó 8.5,6). Nas palavras de Jó, amigo é aquele que intercede em favor daquele que sofre, pois, "o meu intercessor é meu amigo, quando diante de Deus correm lágrimas dos meus olhos; ele defende a causa do homem perante Deus, como quem defende a causa de um amigo" (Jó 16.20,21). Assim, Jó percebe a dura realidade de que, aqueles que se chamam de seus amigos não se oferecem para interceder por ele diante de Deus.

O silêncio dos amigos de Jó teria sido menos danoso que as palavras inúteis que eles proferiram. Jó reclama que

\footnotetext{
o que vocês sabem, eu também sei; não sou inferior a vocês. Mas desejo falar ao Todopoderoso e defender a minha causa diante de Deus. Vocês, porém, me difamam com mentiras; todos vocês são médicos que de nada valem! Se tão-somente ficassem calados, mostrariam sabedoria (Jó 13.2-5).
}

O educador Charles Swindoll (2004, p. 74) argumenta que "os sofredores atraem conselheiros da mesma maneira que as mortes nas estradas atraem corvos". Os discursos vazios e carregados de uma compreensão distorcida de Deus em nada ajudam Jó no seu sofrimento, a ponto de ele preferir o silêncio dos amigos no lugar dos discursos inúteis.

Jó, em meio ao seu sofrimento, sente muita dificuldade em apresentar sua queixa a Deus (Jó 9. 2,3,15-18). Porém, como seus amigos não intercedem por ele diante de Deus, ele mesmo resolve apresentar sua causa. Jó exclama que "minha vida só me dá desgosto; por isso darei vazão à minha queixa e de alma amargurada me expressarei” (Jó 10.1). Jó deixa claro como seria importante que alguém o compreendesse em seu sofrimento e "se tão-somente houvesse alguém para servir de árbitro entre nós, para impor as mãos sobre nós dois, alguém que afastasse de mim a vara de Deus, para que o seu terror não mais me assustasse! Então eu falaria sem medo; mas não é esse o caso" (Jó 10.33-35). Jó queixa-se que "se tão-somente eu soubesse onde encontrá-lo (a Deus) e como ir à sua habitação!” (Jó 23.3). Mas Jó terá que apresentar sua queixa sozinho perante Deus, pois seus amigos não se oferecem a fazê-lo.

Além de não intercederem por Jó diante de Deus, os seus amigos se mostram pessimistas com as possibilidades de seu êxito. Bildade questiona: “como pode então o homem ser justo 
diante de Deus?” (Jó 25.4). Para os amigos de Jó: “seria inconcebível um Jó pobre e miserável e simultaneamente justo e íntegro" (ROSSI, 2008, p. 48). De acordo com o raciocínio dos amigos de Jó, o seu sofrimento só pode ser consequência do pecado. E eles não irão interceder diante de Deus em favor de um pecador. Porém, a experiência de Jó é de que "nem todo mal é castigo por um pecado. O justo também pode viver situações de pobreza e de sofrimento" (ROSSI, 2008, p. 49). Usando de ironia, Jó responde a Bildade que "grande foi a ajuda que você deu ao desvalido! Que socorro você prestou ao braço frágil! Belo conselho você ofereceu a quem não é sábio, e que grande sabedoria você revelou!” (Jó 26.1,2). Os amigos de Jó entendem que ele não teria qualquer chance diante de Deus.

\footnotetext{
Vemos nos diálogos de Elifaz, Bildade, Zofar e Eliú que eles constante e insistentemente falam 'sobre' Deus. Mas é somente nos discursos teológicos de Jó que encontramos alguém falando 'para' Deus. Em meio a sua intensa dor e depressão, Jó abre caminho para se dirigir a Deus. (ROSSI, 2008, p. 85).
}

Aqueles que se chamam de seus amigos, na verdade, falham redondamente ao não intercederem a favor de Jó diante de Deus.

Portanto, observa-se que Jônatas intercede por Davi junto ao rei Saul, ao passo que os amigos de Jó não intercedem por ele diante de Deus. Além de se colocar em risco nesta empreitada, Jônatas argumenta junto ao rei com base nos fatos para assim, obter o favor do rei. Por outro lado, os amigos de Jó lavam as mãos e deixam Jó à sua própria sorte. Jó anseia por um amigo que se solidarize com ele. Aliás, é este o sentido da queixa de Jó quando ele exclama que "eu sei que meu Redentor vive" (Jó 19.25). Seus amigos poderiam ter sido este redentor, assim como Jônatas fora o redentor de Davi diante do rei Saul.

\section{O AMIGO SOLIDÁRIO PROTEGE O AMIGO}

O capítulo 20 de 1 Samuel relata como Jônatas novamente protege seu amigo Davi. Ele precisa fugir do rei Saul para não ser morto. Como Jônatas já havia intercedido a favor de Davi na primeira ocasião reconciliando-o com o rei, Davi recorre ao amigo para entender o que está se passando. E assim, pergunta ao amigo: “O que foi que eu fiz? Qual é o meu crime? Qual foi o pecado que cometi contra seu pai para que ele queira tirar a minha vida?" (1Samuel 20.1b). Novamente, Jônatas não mede esforços para proteger Davi. Davi e Jônatas firmam um pacto de lealdade assegurando a proteção também aos demais familiares. Se, por um lado, Jônatas corre 
riscos para proteger seu amigo da ira do rei, Davi faz uma promessa de proteger os descendentes de Jônatas (1Samuel 20.14-17). Os dois amigos combinam uma estratégia para se comunicarem através de sinais para não levantarem suspeitas de maneira que Davi possa ter sua vida preservada. Davi e Jônatas reafirmam seu compromisso de amizade, pois ambos sabem que Davi é inocente e está injustamente correndo risco de morte. Jônatas, novamente, interpela seu pai na tentativa de livrar a barra de seu amigo (1Samuel 20.32). Porém, desta vez, Jônatas quase paga a amizade com Davi com a própria vida, pois “então Saul atirou sua lança contra Jônatas para matá-lo. E assim Jônatas viu que seu pai estava mesmo decidido a matar Davi” (1Samuel 20.33). O compromisso de amizade entre Davi e Jônatas é evidenciado pela iniciativa de Jônatas em proteger seu amigo.

Por outro lado, os ditos amigos de Jó não estão nem um pouco preocupados em protegêlo em meio ao seu sofrimento. Diante do discurso vazio de Elifaz (Jó 4 e 5), Jó sente-se abandonado. Queixando-se que "vocês de nada me valeram; contemplam minha temível situação, e se enchem de medo" (Jó 6.21). Jó precisa de amigos verdadeiros que o ajudem em sua aflição. Porém, no lugar de oferecerem ajuda, os amigos de Jó somente fazem aumentar sua dor. Jó se sente acusado pelos amigos que deveriam protegê-lo, queixando-se de que "trazes novas testemunhas contra mim e contra mim aumentas a tua ira" (Jó 10.17). Elifaz, em seu segundo discurso, novamente acusa Jó de estar sofrendo como consequência de seu pecado, ao afirmar que: "o seu pecado motiva a sua boca; você adota a linguagem dos astutos. É a sua própria boca que o condena, e não a minha; os seus próprios lábios depõem contra você” (Jó 15.5,6). Diante de acusações tão graves e sem fundamento, Jó constata que "a verdade é que zombadores me rodeiam, e tenho que ficar olhando a sua hostilidade" (Jó 17.2). Eliú, que entra na conversa mais tarde, também falha ao não oferecer auxílio a Jó. Na visão de Eliú, é Deus que necessita de um defensor! Pois Eliú afirma que "mostrarei que se pode dizer mais verdades em defesa de Deus" (Jó 36.2). Jó sente a hostilidade daqueles que se apresentam como seus amigos. Aqueles que deveriam protegê-lo deixam Jó exposto diante de Deus.

Portanto, Jônatas põe sua própria vida em risco para proteger seu amigo Davi, ao passo que os amigos de Jó se negam em oferecer-lhe proteção.

\section{O AMIGO SOLIDÁRIO CONSOLA SEU AMIGO}

Quando Davi precisa se esconder para não ser morto pelo rei Saul, Jônatas vai ao encontro de Davi para consolá-lo. Davi está muito abalado com as constantes tentativas de assassinato da parte do rei Saul. Novamente é com Jônatas que Davi pode contar, pois, "Jônatas, 
filho de Saul, foi falar com ele (Davi), em Horesa, e o ajudou a encontrar forças em Deus" (1Samuel 23.16). Neste momento de angústia, Davi não precisa de lições de moral, mas de alguém que o console e lhe dê forças. Em seu livro Esperança no Sofrimento, os terapeutas Larry Crabb e Dan Allender escrevem que "a profunda intimidade com Cristo, que só o sofrimento pode criar, nos capacita a entrar na vida de outras pessoas com poder de cura" (2000, p. 138). Assim, Jônatas vai ao encontro de Davi e lhe oferece aquilo de que necessita: um consolo autêntico, sem perguntas ou acusações, mas carregado de uma profunda expressão de interesse pelo bem-estar do amigo que está sofrendo.

Bem diferente do consolo proporcionado por Jônatas ao seu amigo Davi, os amigos de Jó deixam claro que não estão dispostos a consolá-lo. Elifaz chama Jó de insensato e tolo (Jó 5.1-3). Bildade vai na mesma linha afirmando que as palavras de Jó "são um grande vendaval" (Jó 8.2). Em seguida, Bildade oferece a Jó um consolo barato ao afirmar que Deus “encherá de riso a sua boca e de brados de alegria os seus lábios" (Jó 8.21). Zofar também não oferece o consolo do qual Jó tanto precisa. Este somente consegue enxergar como Jó está jogando palavras ao vento, e retruca questionando: “como ficarão sem resposta todas essas palavras? Irá confirmar-se o que esse tagarela diz? Sua conversa tola calará os homens? Ninguém o repreenderá por sua zombaria?” (Jó 11.2,3). Jó não aguenta mais as palavras tolas daqueles que deveriam consolá-lo. Jó clama aos seus amigos para que "aquietem-se e deixem-me falar, e aconteça comigo o que acontecer" (Jó 13.13). Assim, Jó nos convida "a renunciar a uma vã tagarelice e a nos calar diante do enigma do sofrimento." (TERNAY, 32). Em seu segundo discurso,

\footnotetext{
Elifaz repreende Jó por ter reagido com ira às tentativas dos amigos de consolá-lo com palavras mansas, as quais, segundo Elifaz, provêm do próprio Deus (Jó 15.11). Elifaz esquece que ele já utilizara de acusações cruéis contra Jó (Jó 5) e que os outros conselheiros foram ainda mais maldosos (BÍBLIA DE ESTUDO NVI, p. 829).
}

Assim, aqueles que se chamam de amigos de Jó, lhe negam o consolo do qual ele tanto necessita.

Jó rebate os falsos consolos recebidos afirmando que "já ouvi muitas palavras como essas. Pobres consoladores são vocês todos!” (Jó 16.2). Jó não precisa de belos discursos, mas de expressões sinceras de consolo, encorajamento e alívio. Se a situação fosse invertida, Jó “procuraria encorajá-los; a consolação dos meus lábios lhes daria alívio" (Jó 16.5). Todas as palavras dos conselheiros são desprezadas por Jó, pois "como podem vocês consolar-me com 
esses absurdos?" (Jó 21.34a). Os amigos de Jó "mostram simpatia, consolam com a boca e tentam acalmar o amigo com simples movimentos de lábios. Mas o que dizem não vale nada" (ROSSI, 2008 p. 57). Desta forma, Jó não é consolado por aqueles que se chamam de seus amigos.

Observa-se, portanto, que Jônatas vai ao encontro de Davi para consolá-lo, ao passo que os amigos de Jó falham nessa tarefa, pois somente ampliam a angústia de Jó com suas acusações.

\section{O AMIGO SOLIDÁRIO SOFRE JUNTO COM O AMIGO}

Davi sofre muito quando recebe a notícia da morte de seu amigo Jônatas. Durante uma das inúmeras lutas contra os filisteus, o rei Saul e seu filho Jônatas morrem em combate. Ao receber a notícia, "Davi rasgou suas vestes; e os homens que estavam com ele fizeram o mesmo. E se lamentaram, chorando e jejuando até o fim da tarde" (2Samuel 1.11,12a). Posteriormente, Davi compôs uma música de lamento onde declara: "como estou triste por você, Jônatas, meu irmão! Como eu lhe queria bem! Sua amizade era, para mim, mais preciosa que o amor das mulheres!” (2Samuel 1.26). Davi compreende que a morte do rei Saul e de seu filho Jônatas representa para ele o fim das perseguições e sua consequente proclamação como o novo rei de Israel. Porém, a dor que Davi sente pela morte de seu amigo é mais forte, e a maneira como Davi sofre no luto confirma a sinceridade de sua amizade com Jônatas.

Os amigos de Jó agem de maneira bem diferente, pois, não há qualquer sinal de que eles estejam compartilhando o sofrimento de Jó. Elifaz argumenta: “como é feliz o homem a quem Deus corrige; portanto, não despreze a disciplina do Todo-poderoso. Pois ele fere, mas trata do ferido; ele machuca, mas suas mãos também curam" (Jó 5.17,18). Elifaz expressa uma frieza cruel. No lugar de sofrer com Jó, Elifaz está mais preocupado em defender suas convicções (Jó 5.27). Para Jó, os conselhos dos amigos soam vazios, pois não há neles qualquer sentimento de compaixão. Jó queixa-se de que "se tão-somente pudessem pesar a minha aflição e pôr na balança a minha desgraça! Veriam que o seu peso é maior que o da areia dos mares. Por isso as minhas palavras são tão impetuosas" (Jó 6.2). Jó queixa-se de que "um homem desesperado deve receber a compaixão de seus amigos, muito embora ele tenha abandonado o temor do Todo-poderoso. Mas os meus irmãos enganaram-me como riachos temporários” (Jó 6.14,15a). Aqueles que vieram para consolar Jó transformam-no em "objeto de riso para os meus amigos, logo eu, que clamava a Deus e ele me respondia, eu, íntegro e irrepreensível, um mero objeto de riso“ (Jó 12.4). 
Jó sente-se traído pelos amigos (Jó 19.19). Em sua situação de abandono, ele exclama: “misericórdia, meus amigos! Misericórdia! Pois a mão de Deus me feriu. Por que vocês me perseguem como Deus o faz? Nunca irão saciar-se da minha carne?” (Jó 19.21,22). "Percebemos que nos discursos dos amigos não há alusão à realidade em que Jó vive e muito menos ao problema da injustiça que ele havia colocado" (ROSSI, 2008, p. 60). Desta maneira, os amigos de Jó permanecem insensíveis, não só ao sofrimento de Jó, mas também aos seus argumentos e lamentos.

Se o luto de Davi inclui não somente seu amigo Jônatas como também o rei Saul que o havia jurado de morte, os conselheiros de Jó permanecem insensíveis ao sofrimento daquele que eles chamam de amigo. Em nenhum momento percebe-se qualquer sinal de que o sofrimento de Jó os tenha atingido emocionalmente. Como Jó anseia por uma amizade como a de Davi e Jônatas!

\section{O AMIGO SOLIDÁRIO É LEAL}

Davi é leal ao seu amigo Jônatas, mesmo depois da morte deste. Algum tempo depois de já ter sido empossado como rei em Israel, Davi cumpre a promessa que havia feito a Jônatas de que honraria sua amizade nas pessoas que descendessem de seu amigo. Quando Mefibosete, filho de Jônatas, compareceu diante de Davi, este lhe disse: "não tenha medo, pois é certo que eu o tratarei com bondade por causa de minha amizade com Jônatas, seu pai. Vou devolver-lhe todas as terras que pertenciam a seu avô Saul, e você comerá sempre à minha mesa" (2Samuel 9.7). Davi cumpre assim uma promessa que havia feito ao seu amigo Jônatas. Ele permanece leal a seu amigo, mesmo quando, talvez aos olhos dos demais, não seria mais cobrado pelas promessas feitas num momento de sofrimento. Mas, para Davi, promessa feita é promessa a ser cumprida.

Diferentemente da atitude de Davi, os amigos de Jó agem em total desacordo com o princípio da lealdade. Jó chega ao ponto de afirmar que: "vocês seriam capazes de pôr em sorteio o órfão e de vender um amigo por uma bagatela!” (Jó 6.27). Pois, os amigos que inicialmente vieram para apoiar Jó em seu sofrimento, agora "abrem sua boca contra mim, esmurram meu rosto com zombaria e se unem contra mim" (Jó 16.10). Aqueles que tratavam Jó com respeito e amizade durante seu período de bonança, se afastam dele assim que a situação já não é mais favorável (Jó 19.14).

Em contrapartida, por mais que Jó esteja sendo traído por seus amigos, ele ainda permanece fiel a eles. Em meio ao seu sofrimento, Jó ainda encontra forças para afirmar que 
“eu os instruirei sobre o poder de Deus; não esconderei de vocês os caminhos do Todopoderoso" (Jó 27.1). "Reconciliando-se com Deus, ele (Jó) vai poder reconciliar-se com os seus amigos" (TERNAY, 2001, p. 323). Assim, mesmo os seus amigos negando-lhe a lealdade, Jó permanece leal àqueles que o estão traindo.

Se, por um lado, a amizade entre Jônatas e Davi é caracterizada pela lealdade que perdura até depois da morte de Jônatas, por outro lado, os amigos de Jó não são leais a ele, ao passo que Jó permanece leal a seus companheiros.

\section{CONCLUSÃO}

O presente artigo identificou seis características cultivadas pelos amigos Davi e Jônatas. A partir do belo exemplo de amizade entre Jônatas e Davi, pode-se concluir que: um amigo solidário expressa sua amizade ao amigo; intercede em favor do amigo; protege seu amigo; consola seu amigo; sofre junto com o amigo; e é leal ao seu amigo.

Aplicando estas características ao relacionamento entre Jó e seus amigos, ficou demonstrado que, no início, seus amigos expressam sua amizade a Jó. Porém, esses não intercedem em favor de Jó diante de Deus, não protegem Jó diante de Deus, não consolam Jó em seu sofrimento, não sofrem junto com ele e lhe são leais.

Desta forma, as atitudes de Elifaz, Bildade, Zofar e Eliú não podem ser caracterizadas como de uma amizade solidária em relação à Jó.

O desfecho da história de Jó apenas confirma como seus amigos estavam distantes dos ideais de amizade. Deus repreende a forma como agiram com Jó, pois diz a Elifaz que "estou indignado com você e com os seus dois amigos, pois vocês não falaram o que é certo a meu respeito, como fez meu servo Jó" (Jó 42.7). Também não foi identificada nas palavras dos amigos de Jó a atitude de conselheiros ou sábios. A melhor designação para Elifaz, Bildade, Zofar e Eliú é de que se trata de meros conhecidos de Jó. Eles sabem quem Jó é, vêm ao seu encontro para prestar-lhe o luto protocolar, mas as demais atitudes não podem ser caracterizadas como de uma amizade solidária.

\section{REFERÊNCIAS}

DICIONÁRIO DO AURÉLIO. Amigo. Disponível em http://www.dicionariodoaurelio.com. Acesso em: 29/05/2010.

BÍBLIA DE ESTUdO NVI. Português. Bíblia Sagrada: Nova Versão Internacional. São Paulo: Editora Vida, 2000. 
CRABB, Larry. Sonhos Despedaçados. São Paulo: Mundo Cristão, 2004.

CRABB, Larry; ALLENDER, Dan. Esperança no Sofrimento. São Paulo: Sepal, 2000.

NEGRI, Antonio. Jó - A Força do Escravo. Rio de Janeiro: Record, 2007.

ROSSI, L. A. S. Jesus vai ao Mc Donalds: Teologia e sociedade de consumo. São Paulo: Fonte Editorial, 2008.

SWINDOLL, Charles. Jó - Um Homem de Tolerância Heróica. São Paulo: Mundo Cristão, 2004.

TERNAY, H. de. O Livro de Jó: Da provação à conversão, um longo processo. Petrópolis: Vozes, 2001. 